\title{
As dimensões do ensino de Geografia da Saúde no Brasil
}

\section{Bruno Porto, Helen Gurgel ${ }^{1}$ and Rafael Catão ${ }^{2}$}

\begin{abstract}
Contexto: A geografia da saúde é uma área de pesquisa que se torna cada dia mais importante, especialmente no Brasil onde a presença de um sistema único de saúde é tema de muitas pesquisas. De modo a conhecer a abrangência do ensino de Geografia e Saúde nos cursos de geografia, foi realizado um estudo para avaliar a disponibilidade de disciplinas sobre essa temática nas universidades públicas brasileiras. Para tal, foi elaborado e enviado aos coordenadores dos cursos de geografia um questionário online e foi realizada entrevistas abertas com professores da área da saúde sobre a utilização da geografia em suas aulas. Resultados: apenas cerca de um terço dos cursos possuem uma disciplina na temática de geografia da saúde, e elas tendem a ser de caráter optativo e não possuir oferta frequente. Além disso, professores da área de saúde afirmaram que utilizam técnicas e saberes de geografia da saúde, mas não conheciam essa temática de pesquisa, pelo menos não por esse nome. Conclusões: apensar do aumento de estudos nessa temática ainda há uma importante lacuna no ensino da geografia da saúde no Brasil, provavelmente devido abaixa institucionalização e divulgação dessa temática. Portanto, recomenda-se um esforço na divulgação e institucionalização dessa temática a partir da oferta de disciplinas e ações de interação da geográfica com cursos da área da saúde.
\end{abstract}

Palavras-chave: Geografia da Saúde, Ensino, Brasil.

\section{Keywords}

Geografia da Saúde, Ensino, Brasil.

\footnotetext{
${ }^{1}$ Universidade de Brasília

${ }^{2}$ Departamento de Geografia, Universidade Federal do Espirito Santo

Corresponding author:

Bruno Porto,

Email: brunolofranoporto@gmail.com
} 


\section{Introduction}

Em 1984 o Professor de Geografia e Epidemiologia Jonathan Mayer da University of Washington em Seattle publicou o artigo "Medical Geography: An Emerging discipline", no qual ele argumenta justamente que a, então, Geografia Medica, era uma disciplina emergente, além de demonstrar várias potencialidades e possíveis temáticas de pesquisa, argumentando principalmente que a Geografia Médica já era utilizada em pesquisas, especialmente epidemiológicas, mesmo que isso não se desse de forma explícita.

Como Barcellos et al mostram em seu artigo de 2018 “Geografia e Saúde: O que está em jogo? Histórias, temas e desafios", não só o termo mais utilizado para a disciplina mudou, de Geografia Médica para Geografia da Saúde, como o próprio pensamento científico da área evoluiu consideravelmente. Dentre alguns dos novos estudos na área destacam-se: os de Jean-Pierre Hervouët sobre as relações entre ambientes e sociedades mostrando o surgimento de áreas de risco à saúde; os trabalhos de Peter Gould sobre doenças sem um nicho específico de difusão, principalmente a AIDS, dentre outros. Esse mesmo artigo traz que:

A geografia da saúde procura compreender o contexto em que ocorrem os problemas de saúde, para poder atuar sobre territórios, não sobre os indivíduos, nem sobre organismos. Diferente de outras disciplinas, a geografia busca uma perspectiva macroscópica dos problemas de saúde, permitindo compreender a dinâmica do processo saúde-doença e de doença-atenção à saúde. A diversidade de temas da geografia da saúde é também resultado dos diversos campos de atuação da Saúde Coletiva, que reúne as ações de vigilância de doenças e seus determinantes, a atenção e organização dos serviços de saúde, e a promoção de saúde, esta última de desenvolvimento relativamente recente. Estudar estes problemas requer uma visão ampliada de saúde, que abarque desde a prevenção de doenças até o acesso a serviços de saúde, isto é, reconhecendo a inseparabilidade do processo de saúde-doençaatenção.

(BARCELLOS et al, 2018.)

Portanto, A Geografia da Saúde é uma disciplina que já evoluiu muito desde sua condição de "emergente" e, é hoje utilizada no âmbito das tomadas de decisões públicas e nos estudos de atenção e de prevenção de doenças. Exemplos claros disso são os boletins epidemiológicos disponibilizados pelo ministério da saúde que atualmente sempre possuem mapas, tabelas de distribuição espacial e outros dados amplamente utilizados na Geografia da Saúde. O volume 52 de janeiro de 2021, por exemplo, apresenta um mapa de casos confirmados de sarampo por estado brasileiro e uma tabela de casos confirmados e óbitos distribuídos por cada estado. Porém, para que as técnicas e abordagens da geografia (GURGEL e LAQUES, 2019) sejam cada vez mais aplicadas na saúde é necessário que os geógrafos formandos pelas universidades brasileiras conheçam as relações entre geografia e saúde e assim possam ofertar os seus conhecimentos as ações de saúde. Neste contexto, o objetivo desse estudo é analisar a oferta de disciplinas na temática de geografia e saúde nos cursos de graduação em geografia no Brasil. 


\section{Metodologia}

De modo a atingir o objetivo proposto a pesquisa foi realizada em múltiplas fases. A primeira foi o levantamento dos cursos de Geografia ofertados nas universidades públicas brasileiras. Esse levantamento foi feito a partir do portal e-MEC. A partir dos dados levantados foram elaborados tabelas e mapas com a distribuição por estado dos cursos catalogados.

Posteriormente, foi elaborado um formulário eletrônico sobre a oferta de disciplinas na temática de Geografia e Saúde que foi enviado via e-mail para os coordenadores dos cursos de geografia catalogados. O questionário ficou disponível entre junho e julho de 2020. O nome dos coordenadores foi obtido através do portal e-MEC, a partir disso buscou-se o contato destes por duas vias principais, o site da instituição ou publicações encontradas no currículo Lattes. O link para o formulário foi enviado para mais de 350 coordenadores de cursos de Geografia. O formulário continha dezenove perguntas, algumas com respostas fechadas outras com respostas abertas e buscava entender se o curso de Geografia coordenado pelo respondente ofertava ou não alguma disciplina na temática de Geografia e Saúde e, em casos positivos, quais as características da oferta e da disciplina em si. A partir dos dados obtidos, foi produzido, tabelas, gráficos e mapas. Todos os mapas foram confeccionados pelo software QGIS em sua versão 3.8 Zanzibar e os gráficos por planilha eletrônica do Excel.

Após essa etapa, foi realizada uma revisão bibliográfica de textos na área de Geografia da Saúde para auxiliar na análise dos resultados obtidos nas etapas anteriores. Alguns textos destacavam que a temática de geografia e saúde ainda era pouco conhecida fora da geografia. Optou-se então por fazer entrevistas com professores de ensino superior da área da saúde com o intuito de saber o que conheciam sobre Geografia da Saúde. Para tal, foram elaboradas cinco perguntas abertas. Essas perguntas foram enviadas para os professores das disciplinas de epidemiologia da Universidade de Brasília (UnB). Foi escolhida essa disciplina e essa universidade por ser a que tem mais conexão com o com grupo de pesquisa que desenvolveu o estudo.

\section{Resultados}

O primeiro levantamento resultou em um total de 354 cursos de Geografia ofertados em universidades públicas brasileiras em junho de 2020, distribuídos espacialmente pelas unidades federativas brasileiras da seguinte forma (figura 1):

Espirito Santo, Rondônia e Tocantins foram os estados que apresentaram o menor número de cursos, com apenas três cursos cada. O Pará foi o estado com maior número de cursos ofertados, com 32, seguido de perto pela Bahia, que teve 30 cursos ofertados.

O questionário elaborado foi enviado para mais de 350 coordenadores e foram obtidas 95 respostas (27\%). Os coordenadores que responderam estão distribuídos por praticamente todas as unidades federativas do Brasil, sendo o Acre o único estado do qual não foi obtida nenhuma resposta ao questionário on-line. Os resultados detalhados desse levantamento também foram divulgados publicamente e podem ser acessados no site do Laboratório de Geografia, Ambiente e Saúde (LAGAS) da Universidade de Brasília (UnB), ou diretamente pela seguinte URL: lagas.unb.br/index.php/disciplinageografia-da-saude-no-brasil.

Dentre as 95 respostas, 37 (38.9\%) afirmaram que o curso oferta pelo menos uma disciplina na temática de Geografia da Saúde (figura 2). Apenas um coordenador de curso informou ofertar mais de uma disciplina na temática de Geografia e Saúde. Este curso foi da Unifesp, que é no formato ABI 


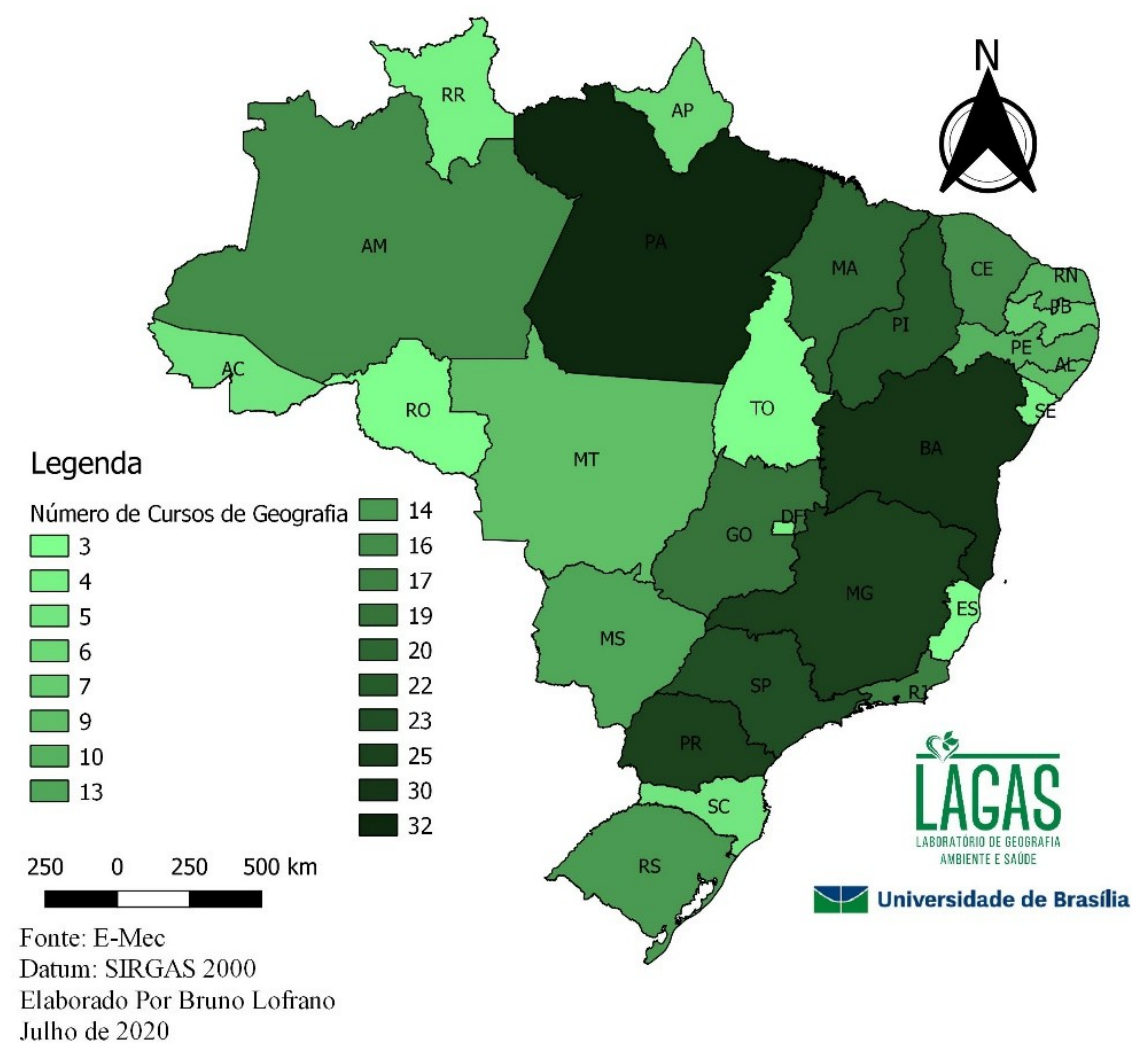

Figure 1. Distribuição dos cursos de Geografia no Brasil

Assim, entre os 95 cursos que responderam ao questionário, tem-se a oferta de 38 disciplinas na temática de Geografia da Saúde. O mapa a seguir (figura 2) mostra a distribuição estadual dos cursos que ofertam pelo menos uma disciplina na temática de Geografia da Saúde, de acordo com o levantamento realizado. Destaca-se o estado do Rio Grande do Norte que tem a oferta em 4 cursos de geografia.

As perguntas seguintes do questionário foram direcionadas a compreender as características da oferta das disciplinas de Geografia da Saúde. Primeiramente, quanto ao próprio nome das disciplinas. Em síntese, foi interessante notar que: 26 disciplinas se chamam, justamente, "Geografia da Saúde"; 4 possuem a palavra "ambiente" no nome; 2 ainda utilizam o termo "Geografia Médica"; um outro nome que chamou muita atenção foi "Geografia da Saúde e Geologia Médica”.

Quanto ao tipo de disciplina (figura 3), ou seja, a obrigatoriedade ou não de cursar a disciplina para completar o curso, identificou-se que a grande maioria das disciplinas era de caráter optativo, 29 disciplinas (76.3\%), 8 eram de caráter obrigatório (21\%) e ainda foi registrada uma disciplina que havia 


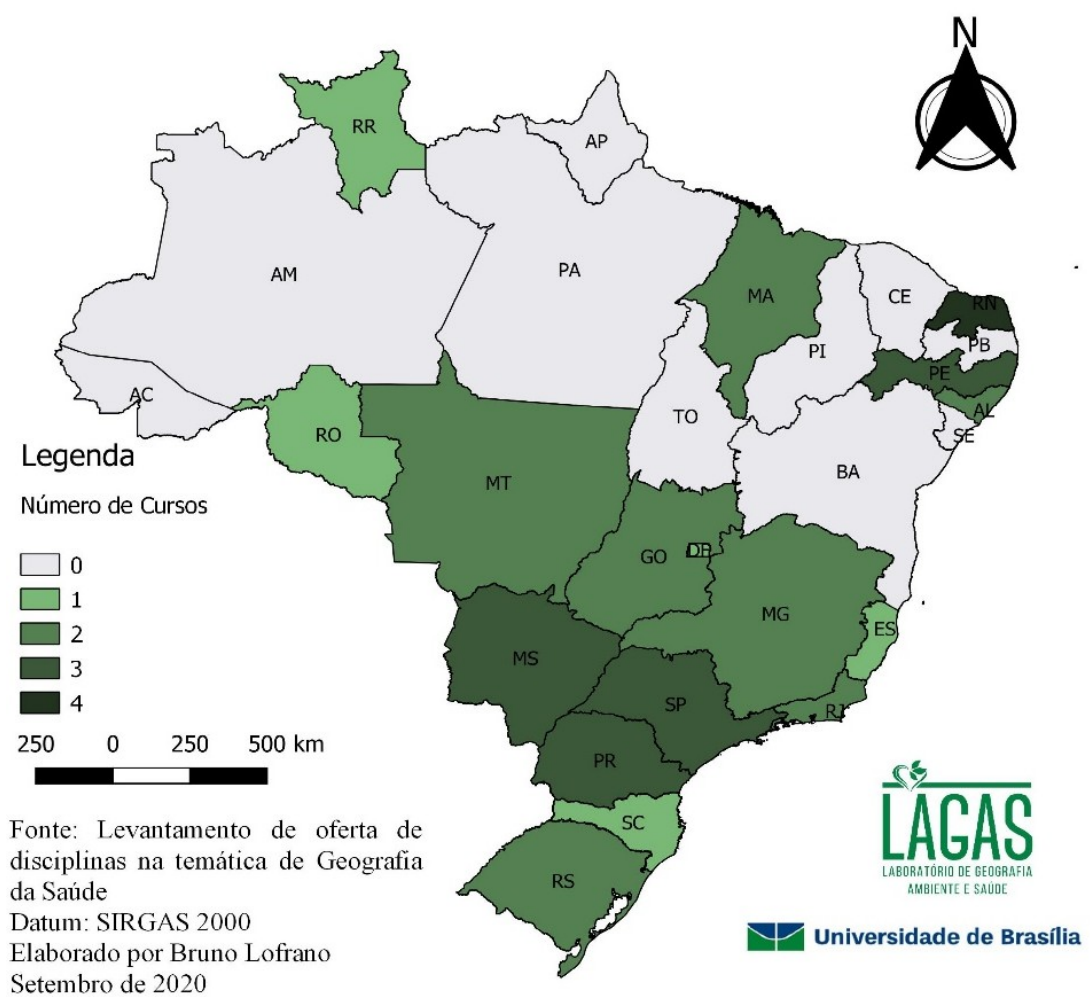

Figure 2. Distribuição dos cursos que ofertam pelo menos uma disciplina na temática de Geografia da Saúde

sido criada em caráter experimental para atender às demandas de discussão a respeito da pandemia de COVID-19.

Com respeito à frequência de oferta (figura 5), observou-se que é comum que a oferta se dê de forma anual ou a cada dois anos; apenas duas disciplinas são ofertadas de forma semestral. Outras duas disciplinas são ofertadas esporadicamente, e 4 disciplinas possuem oferta irregular, baseada na demanda.

Por fim, outras informações para caracterização das disciplinas são as seguintes: 34 disciplinas são ofertadas de forma presencial, apenas 3 são ofertadas na modalidade à distância; quase metade das disciplinas obrigatórias possuem carga horária abaixo de 34h; Apenas duas disciplinas, dentre as obrigatórias, possuem oferta semestral, outras duas possuem oferta baseada na demanda. É importante 


\section{Distribuição do Tipo de Disciplina}

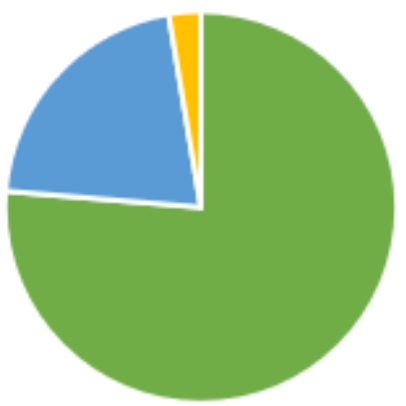

- Optativa

- Obrigatória

- Disciplina especial criada por conta da Pandemia de COVID-19

Figure 3. Tipo de disciplina

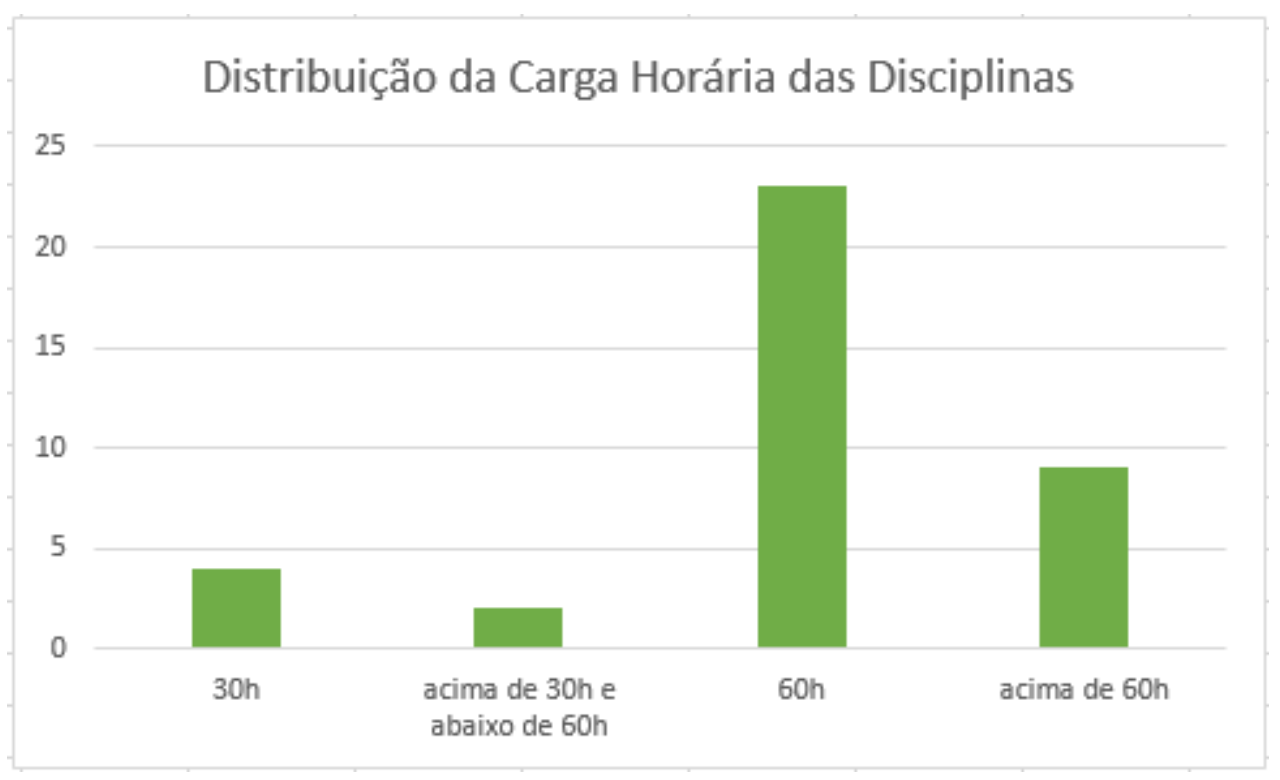

Figure 4. Carga horária das disciplinas 


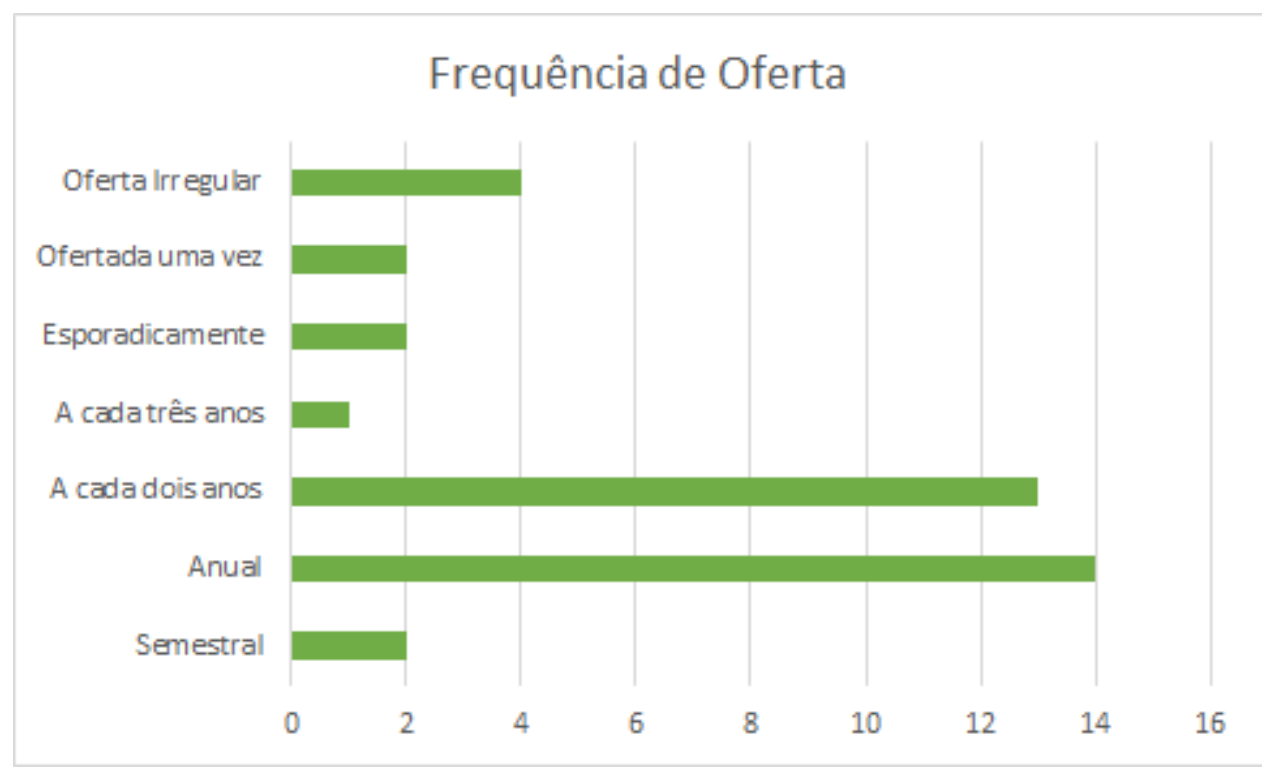

Figure 5. Frequência de oferta

lembrar que esses dados foram coletados no começo da pandemia de COVID-19, quando ainda se esperava uma resolução rápida dessa emergência de saúde pública e as respostas que fazem menção à oferta presencial ou à distância das disciplinas foram dadas considerando a situação pré-pandemia. Como, devido a pandemia, muitas disciplinas passaram a ser ofertadas no modelo remoto seria interessante o desenvolvimento de um novo estudo para avaliar possíveis mudanças que ocorreram nessas disciplinas de Geografia da Saúde durante a pandemia, para avaliar talvez uma mudança na demanda e/ou possíveis alterações nos modelos de oferta.

Avaliando os dados mais relevantes sobre a oferta de disciplinas na temática de Geografia e Saúde, observa-se que o modelo mais comum de oferta das disciplinas é no caráter optativo, com carga horária de 60 horas semestrais e com oferta uma vez ao ano. Dessa forma, devido ao formato de oferta das disciplinas, elas podem ser pouco difundidas e os estudantes tenham pouco oportunidade de cursá-las.

Em relação ao levantamento do conhecimento da temática de geografia e saúde pôr professores da área da saúde, dentre os 10 e-mails enviados para professores de disciplinas de epidemiologia da Universidade de Brasília, obteve-se apenas duas respostas. Um professor informou que leciona as disciplinas de "Epidemiologia Aplicada à Educação Física" na graduação e "Epidemiologia e Atividade Física na Promoção de Saúde" na Pós-Graduação, o outro mestra as disciplinas "informação e informática em saúde 2" e "epidemiologia analítica". Os relatos apresentados por esses professores confirmam que as ferramentas da Geografia da Saúde são bastante utilizadas, dentro da área da saúde, porém não de forma institucionalizada, ou "consciente". Um professor relatou que:

Em ambas [as disciplinas] eu utilizo mapas com distribuição (normalmente de prevalências) de doenças ou de características sociodemográficas, de condições clínicas 
ou de fatores de risco para doenças com alta prevalência. Em particular, são muito comuns mapas que apresentam distribuição do nível de atividade física na população e também mapas de equalização de densidade (density-equalizing maps), que começam a ser muito comuns na apresentação de dados do nível de atividade física da população mundial em associação com outra variável, como a renda ou a quantidade de programas de intervenção existentes em cada país

Outro respondente faz conexão entre fatores geográficos e a prática de atividade física (saúde preventiva):

Ao apresentar o conteúdo da disciplina eu usualmente me reporto às três questões básicas da epidemiologia: quem, quando e onde. Nesta abordagem, eu apresento desfechos que têm conhecidos determinantes ligados a fatores geográficos e ambientais. Essas duas questões são bem identificadas no nível de atividade física da população, que sobre influência de questões territoriais e climáticas, como áreas e períodos do ano que favorecem mais ou menos à prática de atividades físicas. Essas relações são bem exploradas nas disciplinas

Ambos os respondentes comentaram que um tópico de análise em suas aulas é a relação entre fatores ambientais e agravos de saúde, em um caso esses agravos foram doenças e no outro a limitação da prática de atividade física.

Os professores ressaltam a importância do estudo da Geografia para a Saúde, um inclusive comenta já ter trabalhado na produção de mapas de distribuição espacial de indicadores de demanda e gravidade de doenças e até oferece suplementos na nota para alunos que façam um curso sobre QGIS específico.

As duas respostas ressaltaram os benefícios que uma disciplina na temática de geografia da saúde pode trazer para seus alunos, um deles comenta:

tendo em vista que muitas questões em saúde são afetadas por questões geográficas, tanto nos temas mais afeitos à geografia física, quanto àqueles ligados à geografia humana. Seria interessante que [uma disciplina sobre Geografia da Saúde] fosse optativa para todos os cursos da saúde da UnB

Para finalizar, gostaríamos de ressaltar o seguinte comentário feito por um dos respondentes:

Até pouco tempo eu não tinha conhecimento da existência desta disciplina [Geografia, Ambiente e Saúde, ofertada pelo departamento de geografia da UnB] na UnB, assim como não havia focado minha atenção nas possibilidades de interação entre a geografia da saúde e minha área de atuação, a despeito de saber do impacto de inúmeras questões ligadas à geografia, tanto física quanto humana, na saúde humana. Seria interessante uma maior divulgação da área e da disciplina

\section{Discussão}

\section{Importância da geografia da saúde no Brasil}

Apesar da Geografia Médica já existir, provavelmente, desde 1792 (Barcellos, Buzai, \& Handschumacher, 2018), ela só começa a aparecer no Brasil em meados do século XX, com as 
contribuições do médico Josué de Castro que fez doutorado em geografia humana. Seus estudos sobre a subnutrição e fome demonstraram que há um caráter geográfico e geopolítico na manifestação de doenças, e foram uma espécie de primeiro passo para o desenvolvimento da geografia da saúde no Brasil (Mendonça, Araújo, \& Fogaça, 2014). Esses mesmos autores ainda apontam lentidão na disseminação de visões mais amplas para saúde, dentro dos sistemas de saúde brasileiros, mas podemos observar o aumento das intenções de pesquisa em geografia da saúde no Brasil por meio do levantamento feito pelo laboratório LAGAS-UnB, que mostrou a criação de pelo menos 21 novos grupos de pesquisa em Geografia da Saúde desde a publicação desse artigo em 2014. Portanto a Geografia da Saúde no Brasil está em estágio de franco desenvolvimento e pode-se dizer que é uma temática estabelecida no âmbito da geografia e em fase de reconhecimento pelas demais áreas do conhecimento (GURGEL e BELLE, 2020), pelo menos dentro do meio acadêmico. Como destaca a figura 6 , que foi produzida com base no artigo de BARCELLOS, et al. 2018 e que aponta algumas das importantes contribuições teóricas da geografia da saúde ao longo dos anos.

Por volta de 1970, observou-se a mudança de nome, de geografia médica para geografia da saúde, isso se deu por conta da evolução das pesquisas, que mudaram o foco da análise geográfica, passaram a entender saúde de forma mais holística, e deixaram de analisar apenas a doença (Mendonça et al., 2014). No Brasil, esse movimento foi também muito forte, nas décadas de 1970 e 1980, a corrente crítica brasileira deu um certo impulso no desenvolvimento da geografia da saúde nacional principalmente com análises de questões de saúde decorrentes da atividade capitalista (Mendonça et al.,2014).

Além disso, a criação do SUS e a preocupação com a saúde coletiva tiveram e seguem tendo importante papel no desenvolvimento e importância da Geografia da Saúde no Brasil. São múltiplos os estudos de avaliação de efetividade de atendimento ou estudos de vigilância epidemiológica no território brasileiro, dentre diversos outros subtemas da Geografia da Saúde, disponíveis hoje, muitos, inclusive, com contribuições de autores estrangeiros.

Atualmente, percebe-se que existe uma tentativa de expansão de pesquisas na área de Geografia da Saúde, tanto por parte das universidades como por partes de institutos de pesquisa como a Fundação Oswaldo Cruz (FIOCRUZ) e o Instituto de Pesquisa Espaciais (INPE) que, de acordo com levantamento do Laboratório de Geografia, Ambiente e Saúde (LAGAS-UnB), possuem diversos grupos de pesquisa dedicados à Geografia e Saúde e sita no seu site temas de pesquisa como "políticas públicas para saúde em territórios" e "ambiente, ecologia e saúde".

Consulta realizada utilizando os termos "geografia" e "saúde" na base de dados Scielo resultou em 583 artigos, sendo 373 publicados desde 2010, além disso, a base informa que 349 foram publicados no Brasil. A mesma consulta com os termos em inglês ("geography" e "health") em uma das maiores bases bibliográficas da área da saúde (pubmed/medline, na National Library of Medicine dos Estados Unidos) resultou em 24.337 artigos, sendo o primeiro registro no ano de 1857. Entretanto, praticamente $90 \%$ deles foram publicados a partir de 2000 . Sendo que quase $80 \%$ a partir do ano de 2010 , o que mostra o crescimento no número de publicações na área nos anos mais recentes. Porém, é compreensível que a importância da Geografia da Saúde tenha tendência de ser notada principalmente pelas pessoas que atuam nesse campo de pesquisa. Geógrafos fora desse nicho e pessoas da área da Saúde tendem a não perceber a importância da Geografia da Saúde, ainda que muitas vezes utilizem conhecimentos dessa ciência de forma inconsciente. 


\begin{tabular}{|c|c|c|c|c|c|}
\hline $\begin{array}{l}\text { Déc. } \\
\text { de } \\
1790\end{array}$ & $\begin{array}{l}\text { Leonhard } \\
\text { Lugwig Finke } \\
\text { Publicação da } \\
\text { primeira obra } \\
\text { que define o } \\
\text { campo de } \\
\text { estudo da } \\
\text { "Geografia } \\
\text { Médica". }\end{array}$ & $\begin{array}{l}\text { Déc. } \\
\text { de } \\
1830 s- \\
1850 s\end{array}$ & $\begin{array}{l}\text { Epidemiologia } \\
\text { Social } \\
\text { Louis René } \\
\text { Villermé, Edwin } \\
\text { Chadwick, } \\
\text { Friedrich Engels } \\
\text { Rudolf Virchow: } \\
\text { visão higienista } \\
\text { centrada nos } \\
\text { efeitos da Rev. } \\
\text { Industrial. }\end{array}$ & $\begin{array}{l}\text { Déc. } \\
\text { de } \\
1850\end{array}$ & $\begin{array}{l}\text { John Snow } \\
\text { Realizou um } \\
\text { estudo } \\
\text { cartográfico } \\
\text { clássico sobre a } \\
\text { cólera na Broad } \\
\text { Street, } \\
\text { resultando na } \\
\text { rápida redução } \\
\text { da epidemia. }\end{array}$ \\
\hline $\begin{array}{l}\text { Déc. } \\
\text { de } \\
1880- \\
1900\end{array}$ & $\begin{array}{l}\text { Charles Booth } \\
\text { Seus mapas } \\
\text { foram exemplos } \\
\text { da busca por } \\
\text { correlações } \\
\text { espaciais entre } \\
\text { fatores sociais e } \\
\text { a distribuição } \\
\text { dos problemas } \\
\text { de saúde. }\end{array}$ & $\begin{array}{l}\text { Início } \\
\text { Séc. } \\
\text { XX }\end{array}$ & $\begin{array}{l}\text { Max Sorre } \\
\text { Introdução dos } \\
\text { "complexos } \\
\text { patogênicos", } \\
\text { uma série de } \\
\text { relações entre } \\
\text { seres vivos e } \\
\text { ambiente, } \\
\text { viabilizados por } \\
\text { condições } \\
\text { particulares. }\end{array}$ & $\begin{array}{l}\text { Início } \\
\text { Séc. } \\
\text { XX }\end{array}$ & $\begin{array}{l}\text { Evgeny } \\
\text { Pavlovsky } \\
\text { Estudou } \\
\text { endemias de } \\
\text { um ponto de } \\
\text { vista ecológico, } \\
\text { considerando } \\
\text { um equilíbrio } \\
\text { entre o meio } \\
\text { interno e } \\
\text { externo. }\end{array}$ \\
\hline $\begin{array}{l}\text { Déc. } \\
\text { de } \\
1950\end{array}$ & $\begin{array}{l}\text { Jacques May } \\
\text { Ampliou as } \\
\text { definições dos } \\
\text { complexos } \\
\text { patogênicos } \\
\text { com o conceito } \\
\text { de complexos } \\
\text { "geogênicos". O } \\
\text { objetivo ainda } \\
\text { era determinar } \\
\text { áreas de risco } \\
\text { de doenças e } \\
\text { cartografar sua } \\
\text { espacialização. }\end{array}$ & $\begin{array}{l}\text { Déc. } \\
\text { de } \\
1970- \\
2000\end{array}$ & $\begin{array}{l}\text { Jean-Pierre } \\
\text { Hervouët } \\
\text { Estudou a } \\
\text { oncocercose e } \\
\text { doença do sono } \\
\text { em múltiplas } \\
\text { escalas } \\
\text { temporais e } \\
\text { espaciais, com } \\
\text { articulação } \\
\text { interdisciplinar } \\
\text { e abriu caminho } \\
\text { para novos } \\
\text { estudos. }\end{array}$ & $\begin{array}{l}\text { Déc. } \\
\text { de } \\
1980\end{array}$ & $\begin{array}{l}\text { Henri Picheral } \\
\text { Revisita do } \\
\text { conceito de } \\
\text { sistema } \\
\text { patogênico, o } \\
\text { tornando mais } \\
\text { apto a analisar } \\
\text { as diferenças } \\
\text { espaciais da } \\
\text { saúde em } \\
\text { diversas } \\
\text { doenças e } \\
\text { agravos. }\end{array}$ \\
\hline $\begin{array}{l}\text { Déc. } \\
\text { de } \\
1980\end{array}$ & $\begin{array}{l}\text { Peter Gould } \\
\text { Conceitos chave } \\
\text { de organização } \\
\text { espacial e } \\
\text { dinâmica } \\
\text { socioespacial } \\
\text { sobre a } \\
\text { distribuição de } \\
\text { doenças. }\end{array}$ & $\begin{array}{l}\text { Déc. } \\
\text { de } \\
1990\end{array}$ & $\begin{array}{l}\text { Gerard Salem } \\
\text { Desenvolveu } \\
\text { uma reflexão } \\
\text { sobre o } \\
\text { propósito dos } \\
\text { geógrafos da } \\
\text { saúde e a } \\
\text { compreensão } \\
\text { dos territórios } \\
\text { de saúde. }\end{array}$ & & \\
\hline
\end{tabular}

Figure 6. Linha do tempo de contribuições para geografia da saúde 


\section{Ensino de geografia da saúde no Brasil}

Primeiramente, é importante ressaltar que essa análise foi feita com base em dados da amostra de respondentes e não do total da população pretendida. Como foi citado, nem todos os cursos de Geografia ofertados no Brasil responderam à pesquisa. No total, um quarto dos cursos disponíveis, segundo o MEC, responderam ao questionário. Os dados obtidos, apesar de não caracterizarem uma amostra aleatória, não possuem nenhum fator que afete a validade dos mesmos visto que todos foramigualmente convidados a participar e todas respostas foram incluídas. Há que se admitir a possibilidade de um viés de participação, visto que os coordenadores de curso que possuem alguma disciplina de Geografia da Saúde poderiam ser mais propensos a responder o questionário do que os coordenadores de cursos que não tem ligação com essas disciplinas. Entretanto, esta possibilidade provavelmente não afetou demasiadamente a participação, uma vez que menos de $30 \%$ dos respondentes afirmaram que o curso oferta alguma disciplina do tipo. É também interessante lembrar que não houve respostas oriundas de todas as unidades da federação. Além do Acre não ter retornado nenhuma resposta, houve estados que apresentaram apenas um respondente. Dessa forma, sugere-se que as próximas análises sejam feitas a partir de uma escala mais abrangente, considerando o Brasil como unidade de análise.

Como citado anteriormente, dentre as respostas recebidas, 37 de um total de 95 coordenadores responderam que o curso possui pelo menos uma disciplina na temática de Geografia da Saúde. Assim, de modo aproximado e extrapolando nossos dados para todo o território nacional, é plausível estimar que deva existir cerca de $40 \%$ dos cursos de geografia no cenário nacional que contemplem esta temática em disciplinas. Considerando essa hipótese, deve haver no Brasil algo entre 140 e 150 cursos de Geografia com disciplinas na temática de Geografia da Saúde.

Assim, mesmo com a importância que a Geografia da Saúde tem hoje no âmbito das decisões públicas, e dentro da academia, ainda há uma considerável lacuna no ensino dessa subárea da Ciência Geográfica.

Um ponto relevante que não foi considerado para esse estudo, mas pode ser desenvolvido em um estudo futuro é o da formação dos professores que lecionam as disciplinas com temáticas de Geografia e Saúde. Como os respondentes do questionário de avaliação foram os coordenadores ou coordenadoras de cursos de geografia, sabemos que as disciplinas em questão são todas ofertadas pelos departamentos de geografia (é provável que algumas universidades utilizem um nome diferente par a unidade acadêmica) das universidades, portanto, é provável que a maioria dos professores tenha formação na área de geografia, provavelmente um curso de graduação em geografia e a formação em pós-graduação já com direcionamento para a geografia da saúde. Todavia, nada impede que as universidades contratem professores ou professoras que tiveram uma formação inicial em outras áreas para lecionar as disciplinas em geografia da saúde, isso pode apresentar inclusive algumas vantagens. Por exemplo, considerando uma universidade que ainda não possui uma disciplina nessa temática, mas está desenvolvendo processo seletivo para contratar um profissional para montar e lecionar uma nova disciplina nessa área. Essa universidade pode se beneficiar contratando alguém que é formado em saúde coletiva, por exemplo, com pós-graduação em geografia da saúde.

Em um cenário ideal, onde várias universidades já ofertem disciplinas na temática de geografia da saúde, possivelmente várias delas de forma obrigatória, pode ser também interessante a oferta de disciplinas optativas sobre temas específicos da geografia da saúde, por exemplo uma disciplina de epidemiologia aplicada a geografia da saúde. Disciplinas com temática mais específicas, podem ser muito importantes para o maior desenvolvimento da rede de ensino de geografia da saúde e podem ser ofertadas tanto por professores com formação em outras áreas contratados pelos departamentos de 
geografia, como podem ser ofertadas diretamente por outros departamentos, e possuírem caráter optativo e vagas dedicadas para estudantes de geografia. Tudo isso dito, é importante lembrar que no cenário atual, de pouca oferta de disciplinas na temática de geografia da saúde, o mais importante é a disseminação e a criação de disciplinas de caráter um pouco mais geral e introdutório.

Também é notório que, dentro do contexto do ensino superior em nível de graduação, a Geografia da Saúde tende a ter mais importância para o Bacharelado do que para a Licenciatura, já que é mais comum os formandos licenciados trabalharem ao nível de ensino básico e médio, onde a Geografia da Saúde talvez seja considerada menos relevante, até por não ser contemplada na Base Nacional Comum Curricular, ainda que existem vários benefícios ao ensino de Geografia da Saúde no ensino médio, como mostram PASTORIZA e SILVA (2014) no texto "O Ensino Interdisciplinar do Tema Dengue: Uma Proposta para a Geografia" e SOARES e BEZERRA (2019) em "Saúde urbana no ensino de geografia: um relato de experiência no município de Olinda, Brasil”. Ainda assim, um bom número de cursos que ofertem disciplinas nessa temática seria algo em torno de 250.

Os resultados desse estudo mostram que a Geografia da Saúde ainda é pouco disseminada em relação a oferta de disciplinas para a graduação. Assim, há um grande campo para a expansão dessa temática, em especial através da rede de ensino. Apesar dos conhecimentos desse campo já serem utilizados, poucos ainda o relacionam com a geografia e a potencialidade que se teria em fazer parceria com essa ciência. Nesse contexto, para que a Geografia da Saúde seja mais disseminada, recomenda-se o fortalecimento dos grupos de pesquisa, assim como uma maior publicização dos congressos e conferências e que a disciplina seja institucionalizada nos cursos de geografia. Importante ressaltar também que a divulgação da geografia da saúde deve ser feita com foco não somente para estudantes de cursos de geografia, mas também para todas as áreas adjacentes e que podem se beneficiar desse tipo de abordagem em saúde com foco na visão espacial, e, pelo caráter interdisciplinar da própria ciência geográfica.

Ressalta-se que os temas da Geografia da Saúde tendem a ser abordados e discutidos em outras disciplinas dos cursos, tanto de Geografia como da área da Saúde. Deste modo, o ensino de Geografia da Saúde já pode estar um pouco melhor institucionalizado do que esses números sugerem. Ou seja, é bastante provável que os alunos de Geografia, por exemplo, estudem técnicas, trabalhos ou temas relacionados à Geografia da Saúde dentro de outras disciplinas, tais como, disciplinas sobre cartografia, geoprocessamento, climatologia, planejamento urbano, geografia agrária, dentre várias outras.

Um último comentário, apesar do levantamento realizado sobre disciplinas de Geografia da Saúde não ter obtido dados do estado do Acre, vale mencionar que um estudo de 2014 teve justamente como objetivo a avaliação do ensino de Geografia da Saúde no Acre. A conclusão foi de que não havia nenhuma disciplina nessa temática nos cursos de bacharelado e licenciatura em Geografia na Universidade Federal do Acre (UFAC), além disso, pouquíssimos alunos entrevistados já tinham ouvido falar sobre Geografia da Saúde. O estudo fez a divulgação da temática e promoveu um minicurso (Farias, 2014). Isso é bastante significativo já esses dois cursos analisados no estudo representam $66 \%$ dos cursos de geografia do estado.

\section{Considerações finais}

Os levantamentos realizados, bem como as entrevistas feitas, sugerem que a Geografia da Saúde, área de pesquisa dentro da Ciência Geográfica já está francamente estabelecida no Brasil e tem sua importância evidenciada no âmbito acadêmico e da saúde pública e coletiva. Entretanto, carece de disciplinas específicas nos cursos de geografia das universidades públicas brasileiras. Dessa forma, recomenda-se 
uma maior divulgação da temática junto aos formadores dos futuros geógrafos e professores de geografia brasileiros, a fim de institucionalizar a Geografia da Saúde, através da oferta de disciplinas, de modo a consolida-la como área de pensamento e pesquisa específica da Geografia no Brasil.

\section{Agradecimentos}

O presente trabalho foi realizado no âmbito do Laboratório de Geografia, Ambiente e Saúde (LAGAS) da UnB e contou com apoio do CNPq través do financiamento de bolsa PIBIC e do Laboratório Misto Internacional | LMI-Sentinela uma parceria entre o IRD-UnB-Fiocruz (www.lmi-sentinela.unb.br).

\section{References}

(2021). SciELO | Scientific Electronic Library Online.

Barcellos, C., Buzai, G. D., \& Handschumacher, P. (2018). (Vol. 37). Retrieved from https : / / doi.org/10.4000/confins.14954

Da, E. M. (2018). Retrieved from http: / / basenacionalcomum.mec.gov.br/

Farias, C. S. (2014). O ensino da geografia da saúde no Acre. Hygeia - Revista Brasileira de Geografia Médica e da Saúde, 10, 250-263.

Gurgel, H., \& Belle, N. (2019). Retrieved from https: / / repositorio.unb.br/handle/ $10482 / 35935$

Gurgel, H., \& Laques, A. E. (2019). (Vol. 42). Retrieved from https : / / doi . org/10 . 4000 / confins.22814

Lagas-Unb. (2021). Retrieved from http://lagas.unb.br/index.php/grupos -geosaude/grupos-pesquisas-geosaude-r

Mayer, J. D. (1984). Medical Geography: An Emerging Discipline. JAMA(20), 2680-2683.

Mendonça, F., Araújo, W. M., \& Fogaça, T. K. (2014). A geografia da saúde no Brasil. Estado da arte e alguns desafios. Investigaciones Geográficas, 48, 41-52.

Nacional Library of medicine. U.S. Department of Health and Human Services, National Library of Medicine. (2021). National Center for Biotechnology Information.

Pastoriza, T. B., \& Silva, E. N. (2014). O ensino interdisciplinar do tema da dengue: Uma proposta para a geografia. Hygeia - Revista Brasileira de Geografia Médica e da Saúde, 10, 71-81.

Portal, F. ., \& Fiocruz. (2021). (áreas de pesquisa, Ed.). Retrieved from https: / portal . fiocruz .br/areas-de-pesquisa

Saúde, S. D. V. E. (2021). N 2: Informe semanal sarampo - Brasil, semanas epidemiológicas 1 a 53. 2020 e vigilância laboral dos arbovírus. Brasil, Ministério da Saúde. Boletim Epidemiológico, 52. Soares, J. R. H. S., \& Bezerra, A. C. V. (2019). (Vol. 42). Retrieved from https : / / doi . org/ $10.4000 /$ confins.23081 